\title{
Prognostic Impact of Different Subtypes of Severe Aortic Stenosis after Transcatheter Aortic Valve Implantation
}

\author{
Matyas Pal ( $\sim$ palm@kardio.hu ) \\ Gottsegen National Cardiovascular Center https://orcid.org/0000-0001-7434-6643 \\ Gabor Dekany \\ Gottsegen National Cardiovascular Center
}

\section{Sai Satish}

Apollo Hospitals Chennai

\section{Adrienn Mandzak}

Gottsegen National Cardiovascular Center

\section{Zsolt Piroth}

Gottsegen National Caridovascular Center

\section{Geza Fontos}

Gottsegen National Cardiovascular Center

\section{Peter Andreka}

Gottsegen National Cardiovascular Center

\section{Original Article}

Keywords: Aortic stenosis, TAVI, low-flow, survival

Posted Date: February 9th, 2021

DOl: https://doi.org/10.21203/rs.3.rs-195164/v1

License: (9) This work is licensed under a Creative Commons Attribution 4.0 International License. Read Full License 


\section{Abstract}

\section{Purpose}

Outcomes for different subtypes of aortic stenosis (AS) after transcatheter aortic valve implantation (TAVI) are still subjects of debate. The aim of the study was to evaluate the prognostic impact of baseline flow rate $(F)$ and mean gradient $(G)$ on survival after TAVI.

\section{Methods}

From 2008. to 06. 2017. TAVI was performed in 300 cases ( 127 men, 173 women, age $80,0 \pm 5,8$ years) with severe AS. Follow-up was at least 3 years. Mortality tracking was $100 \%$. Patients were divided into high gradient (HG: 237), low-flow low-gradient (LF-LG: 41), paradoxically low flow-low gradient (PLF-LG: 9) and normal flow-low gradient (NF-LG: 13) groups. Primary endpoint was 30-day, 1-year and 3-year allcause mortality (M) .

Results

NF-LG had better prognosis (M: 30d 0, 1-year: 7,7\%, 3-year: 46,2\%). In HG patients mortality was low in the 1st year (30-day: 3,8\%, 1-y: 14,3\%), but higher (62,8\%) after 3 year. PLF-LG had intermediate outcomes (30-day 0, 1-year 22,2\%, 3-year 55,6\%). LF-LG had the highest mortality (30-day 12,2\%, $p=0,03,1$-year $34,2 \% p=0,005,3$-year $75,6 \% p=0,009$ vs.HG) and relative risk $(2,44[1,34-4,42] p=0,003$ vs.HG). Independent predictors of 1-year mortality were only Grade $2+$ paravalvular regurgitation $(p=0,04)$ and severe renal dysfunction $(p=0,04)$.

\section{Conclusions}

TAVI survival is determined by the guideline-defined subtype of AS. Low flow - low gradient AS is associated with worse prognosis, therefore these patients need careful management after TAVI.

\section{Introduction:}

Severe aortic stenosis (AS) is the most common valvular disease with considerable impact on morbidity and mortality, and with increasing prevalence. According to the current guidelines, severe AS is defined with aortic valve area (AVA) $1.0 \mathrm{~cm}^{2}$, aortic mean gradient $40 \mathrm{mmHg}$, and peak aortic velocity $4.0 \mathrm{~m} / \mathrm{s}$ [1.]. In case of low output lower mean gradient may occur. Hence, beyond the classical definition, different clinical entities of AS were later described [2.-4.]. Each type of AS is characterized by different clinical presentation and prognosis [4.-6.]. Stages of AS and current recommendations for intervention are based primarily on AVA, mean Gr and peak CW jet velocity, and secondarily on stroke volume index (SVI) and LVEF [7.,8.]. In the last decade there was a growing evidence, that transvalvular flow can be more important than EF, therefore a new classification of AS became reasonable [9.]. This idea is now widely accepted and incorporated in the current guidelines [7.,8.] Nevertheless, all patients with severe symptomatic AS have poor prognosis without valve replacement [10.]. For patients with prohibitive, high 
or intermediate operative risk, transcatheter aortic valve replacement (TAVI) can be an alternative solution [11.].

Despite the favorable outcome and hemodynamic results after TAVI, a considerable proportion of patients die within the first 2 years [11.]. Therefore, it is of particular importance to identify patients who may benefit from this treatment indeed. Surgical scores have not been validated to predict mortality after TAVI [12.]. Further risk scores have been developed, specifically for TAVI patients [13.-14.], however, these systems are not widely accepted and used. Several studies revealed that reduced SVI may be an independent predictor of mortality after TAVI [15.,16.]. In addition, there have been similar conclusions regarding the impact of low ejection fraction (EF) and low gradient (LG) on outcomes after TAVI [17-19.]. Further extension of indication for TAVI can be expected in the near future in a significant part of low-risk AS patients, considering the positive results of the latest large low-risk TAVI trials [20.21.]. In this group long-term success is determined mostly by initial hemodynamic (i.e. echocardiographic) parameters and periprocedural complications rather than severe comorbidities.

The objectives of this study were to evaluate the prognostic impact of different SVI - gradient patterns on outcomes of TAVI, as well as the changes in left ventricular function.

\section{Methods:}

Patients and Procedures

The present study included all (n 300) patients between 2008 and June 2017, with symptomatic (NYHA class II.-IV.) severe AS (mean $\mathrm{Gr} \geq 40 \mathrm{~mm} \mathrm{Hg}$, or an aortic valve area of $<1.0 \mathrm{~cm}$, or $<0.6 \mathrm{~cm}^{2} / \mathrm{m}^{2}$ ) undergoing TAVI in our Institute. All patients were evaluated for TAVI by the 'Heart Team'. In all patients, clinical assessment, transthoracic echocardiography, coronary angiography and multislice computed tomography were performed before the procedure.

The present study was accepted by the local ethics committee and all patients provided written informed consent.

Clinical and echocardiographic examinations of patients were performed within 7 days before TAVI and 12 months after implantation. All patients were followed for at least 3 years. Mortality tracking was achieved in $100 \%$ of patients. Mortality data were obtained in all cases from the Registry of the National Health Care System.

The primary endpoints were 30-day, 1-year and 3-year all-cause mortality after TAVI. In addition, secondary endpoint was the change of LVEF in the survivors.

Patients were subdivided into groups depending on their SVI - Gr pattern. High gradient was considered if the mean Gr was $>/=40 \mathrm{mmHg}$, and low Gr if it was $<40 \mathrm{mmHg}$. Low flow was defined with $\mathrm{SVI}</=35$ $\mathrm{ml} / \mathrm{m}^{2}$, and normal flow with $\mathrm{SVI}>35 \mathrm{ml} / \mathrm{m}^{2}$. Patients were divided into four groups: 
HG: high gradient; regardless of EF or SVI

LF-LG: low flow - low gradient; and LVEF $<50 \%$

PLF-LG: low flow - low gradient and LVEF >/= 50\%

NF-LG: normal flow-low gradient.

Transcatheter aortic valve implantation

TAVI was performed in 300 patients (native AS, n 294; degenerated bioprosthesis, n 6). Medtronic CoreValve prosthesis was inserted in 285 cases, Edwards-Sapient valve in 2 cases, Medtronic Engager in 8 cases and Lotus prosthesis in 7 cases. Access site for TAVI was transfemoral in 287 cases, transapical in 8 cases and direct transaortic in 5 cases.

\section{Echocardiography}

Comprehensive 2-dimensional and Doppler echocardiographic studies were performed on ultrasound equipment IE33, Phillips Healthcare, Andover, MA in accordance with the European Association of Echocardiography guidelines [1., 22.].

For each study, multiple transducer positions were used routinely for measurement of aortic gradient. Heart valve insufficiencies were evaluated according to the recommendations of the European Association of Echocardiography. Left ventricular ejection fraction was measured by biplane Simpson method from four- and two-chamber views.

All TAVI implantations were monitored with transesophageal echocardiography. Besides valve positioning, hemodynamics and possible complications, we carefully evaluated the cause and the degree of paravalvular aortic regurgitation (AR) according to the WARC-2 criteria [23.]. Measuring the circumferential extent of paravalvular jet(s) mild AR was defined $<10 \%$, moderate AR $10-29 \%$ and severe $A R>/=30 \%$. Different grades of paravalvular AR are illustrated on Fig. 1. .

\section{Statistical analysis}

Numerical values are expressed as mean + standard deviation (SD) or median. Continuous variables were compared between groups using an unpaired t-test (for normally distributed variables). Continuous variables were compared using the paired Student's t-test before and after TAVI. Time-to-event data analysis was done using the Cox proportional hazards model. Survival curves were constructed for timeto-event variables using Kaplan-Meier estimates and compared by the log-rank test. The association between mortality and baseline clinical, echocardiographic and periprocedural variables was assessed with the use of Cox proportional hazard analysis. Variables with a $p$ value $<0.10$ in univariable analysis were entered into the multivariable model. All reported probability values are two tailed, and $\mathrm{P}<0.05$ was 
considered statistically significant. Analyses were performed with the SPSS statistical software package (version 24.0).

\section{Results:}

Patient characteristics:

The mean age of patients (173 women, 127 men) was $80,0+/-5,8$ years. Because of porcelain aorta 16 patients had contraindication for open-heart surgery. In the 284 high-risk cases the logistic EuroSCORE was $19,7+/-12,6$. The AVA was $0,54+/-0,16 \mathrm{~cm}^{2}$, the mean $\mathrm{Gr} 50,9+/-17,6 \mathrm{mmHg}$ and the mean $\mathrm{EF}$ was $54,3+/-14,0 \%$.

Time to follow-up was median 34 months (0-115 months)

The HG AS subgroup included 237 cases (79\%), the LF-LG AS 41 cases $(13,67 \%)$, while only 9 patients (3\%) fulfilled PLF-LG and 13 (4,33\%) NF-LG criteria. Subgroups are illustrated in Table 1.

Table 1

Patient subgroups

\begin{tabular}{|ll|}
\hline HG & NF-LG \\
Mean gradient $>/=40 \mathrm{mmHg}$ & $\mathrm{SVI}>35 \mathrm{ml} / \mathrm{m}^{2}$ \\
$\mathrm{~N}: 237$ (79\%) & Mean gradient $<40 \mathrm{mmHg}$ \\
& $\mathrm{N}: 13(4,33 \%)$ \\
\hline PLF-LG & LF-LG \\
LVEF $>/=50 \%, S V l</=35 \mathrm{ml} / \mathrm{m}^{2}$ & $\mathrm{SVI}</=35 \mathrm{ml} / \mathrm{m}^{2}$ \\
Mean gradient $<40 \mathrm{mmHg}$ & Mean gradient $<40 \mathrm{mmHg}$ \\
$\mathrm{N}: \mathbf{9}(3,0 \%)$ & $\mathrm{N} \mathrm{41}(13,67 \%)$ \\
\hline
\end{tabular}

HG AS patients were significantly older, had smaller AVA,. From the 237 HG cases 127 (53,6\%) had low SVI. In the LF-LG group the prevalence of NYHA class IV., myocardial infarction, peripheral artery disease was higher, and these patients had larger end-diastolic and end-systolic volumes and lower EF compared to HG-AS group. In the PLF-LG group the ESV was smaller and the EF was higher than in the HG patients. In the NF-LG group the EDV and ESV was significantly higher than in the HG group. Baseline clinical and hemodynamic characteristics of patients and the differences between groups are shown on Table 2 . 
Table 2

Baseline clinical and hemodynamic characteristics

\begin{tabular}{|c|c|c|c|c|c|}
\hline & HG 237 & LFLG 41 & PLFLG 9 & NFLG 13 & p \\
\hline Male & $8937,5 \%$ & $2765,9 \% *$ & $444,4 \%$ & $753,8 \%$ & 0,027 \\
\hline Age & $80,4+/-5,6$ & $78,6+/-5,8^{*}$ & $77,8+/-7,7^{*}$ & $78,2+/-6,6^{*}$ & 0,02 \\
\hline Euroscore II. & $17,5+/-11,5$ & $27,3+/-15,2^{*}$ & $20,7+/-16,7$ & $16,3+/-13,9$ & 0,002 \\
\hline Porcelain aorta & $114,6 \%$ & $24,8 \%$ & $111,1 \%$ & $215,4 \%$ & ns. \\
\hline NYHA class IV. & $5924,9 \%$ & $2356,1 \% *$ & $333,3 \%$ & $323,1 \%$ & 0,008 \\
\hline CAD & $16870,9 \%$ & $3380,5 \%$ & $888,9 \%$ & $1184,6 \%$ & ns. \\
\hline Previous MI. & $4418,6 \%$ & $1434,1 \% *$ & $111,1 \%$ & $17,7 \%$ & 0,013 \\
\hline PCl. & $4519,0 \%$ & $1741,4 \%$ & $444,4 \%$ & $323,1 \%$ & ns. \\
\hline CABG & $2611,0 \%$ & $614,6 \%$ & $111,1 \%$ & $323,1 \%$ & ns. \\
\hline $\begin{array}{l}\text { Mitral arteficial } \\
\text { valve }\end{array}$ & $31,2 \%$ & $24,9 \%$ & 0 & 0 & ns. \\
\hline $\begin{array}{l}\text { Aortic } \\
\text { bioprosthesis }\end{array}$ & $62,4 \%$ & 0 & 0 & $17,7 \%$ & ns. \\
\hline Diabetes mellitus & $7431,2 \%$ & $1741,4 \%$ & $333,3 \%$ & $430,8 \%$ & ns. \\
\hline Atrial fibrillation & $9138,4 \%$ & $2253,7 \%$ & $222,2 \%$ & $538,4 \%$ & ns. \\
\hline $\mathrm{GRF}<30 \mathrm{ml} / \mathrm{min}$ & $3615,2 \%$ & $1126,8 \%$ & $333,3 \%$ & $430,8 \%$ & ns. \\
\hline PAD & $145,9 \%$ & $819,5 \%$ * & $222,2 \%$ & $215,4 \%$ & 0,017 \\
\hline TIA/Stroke & $8234,6 \%$ & $1741,4 \%$ & $222,2 \%$ & $323,1 \%$ & ns \\
\hline COPD & $4519,0 \%$ & $1229,3 \%$ & $333,3 \%$ & $215,4 \%$ & ns \\
\hline $\mathrm{PM} / \mathrm{ICD}$ & $83,4 \%$ & $1536,6 \% *$ & $111,1 \%$ & $215,4 \%$ & 0,0001 \\
\hline $\mathrm{EDV}(\mathrm{ml})$ & $116,2+/-32,2$ & $146,3+/-54,0 *$ & $86,2+/-19,8$ & $162,5+/-48,9 *$ & 0,005 \\
\hline ESV $(\mathrm{ml})$ & $51,7+/-25,9$ & $102,2+/-40,6^{*}$ & $\underset{\star *}{30,7+/-12,8}$ & $95,3+/-29,3^{*}$ & $\begin{array}{l}0,005 / \\
* \star 0,02\end{array}$ \\
\hline EF (\%) & $58,3+/-13,5$ & $30,2+/-7,6^{*}$ & $64,4+/-6,2$ ** & $41,4+/-9,5$ & $\begin{array}{l}0,0001 / \\
\star * 0,02\end{array}$ \\
\hline Area $\left(\mathrm{cm}^{2}\right)$ & $0,51+/-0,14$ & $0,59+/-0,14$ & $0,65+/-0,13^{*}$ & $0,71+/-0,19 *$ & 0,002 \\
\hline Gradient (mmHg) & $57,0+/-13,5$ & $28,7+/-7,1^{*}$ & $33,1+/-4,5^{*}$ & $31,7+/-6,2^{*}$ & 0,0001 \\
\hline $\mathrm{SVI}\left(\mathrm{ml} / \mathrm{m}^{2}\right)$ & $35,4+/-11,1$ & $24,6+/-5,3^{*}$ & $29,9+/-5,2^{*}$ & $43,8+/-9,5$ & 0,0001 \\
\hline
\end{tabular}




\section{HG 237 \\ p: vs. HG}

LFLG 41

PLFLG 9

NFLG 13

p

Abbreviations: CAD: coronary artery disease, MI: myocardial infarction, $\mathrm{PCl}$ : percutaneous coronary intervention, CABG: coronary artery bypass grafting, PAD: peripheral artery disease, COPD: chronic obstructive pulmonary disease, EDV: left ventricular end-diastolic volume, ESV- end-systolic volume,

Mortality after TAVI:

Periprocedural death occurred in 1 case in the HG group (0,33\%), 30-day all-cause mortality was 4,33\% (n 13), 1-year mortality was $17,0 \%$ (n 51), and primary endpoint was reached at 3-year in 62,0\% (n 186). HG AS had better 30-day ,1-year and 3-year mortality compared to LF-LG (30d: 3,8\% vs 12,2\% p =0,03, 1-year $14,3 \%$ vs $34,2 \% p=0,0053$-year $62,2 \%$ vs. $75,6 \% p=0,009$ ). PLF-LG patients had intermediate outcomes (1-y $22,2 \%, 3-y 55,6 \%)$. The NF-LG group had the best outcomes, but because of the small number of endpoints the difference was not significant. The differences in mortality rates between subgroups are demonstrated on Table 3.

Table 3

Mortality of the subgroups

\begin{tabular}{|lllll|}
\hline & Periprocedural & 30. day & 1 year & 3 year \\
\hline HG 237 & $1(0,33 \%)$ & $9(3,8 \%)$ & $34(14,3 \%)$ & $149(62,2 \%)$ \\
\hline LF - LG 41 & 0 & $5(12,2 \%) p=0,03$ & $14(34,2 \%) p=0,005$ & $31(75,6 \%) p=0,009$ \\
\hline PLF - LG 9 & 0 & & $2(22,2 \%)$ & $5(55,6 \%)$ \\
NF - LG 13 & 0 & & $1(7,7 \%)$ & $6(46,2 \%)$ \\
All 300 & $1(0,33 \%)$ & $14(4,33 \%)$ & $51(17,0 \%)$ & $191(62,0 \%)$ \\
\hline & $p$ : vs. HG & & & \\
\hline
\end{tabular}

Kaplan Meier survival curve of the whole patient group is demonstrated on Fig. 2. Survival curves of different subgroups of AS are shown on Fig. 3. Differences in survival between HG and LF-LG groups is demonstrated on Fig. 4.

Predictors of mortality:

Because of the course of mortality rates, we considered of importance the assessment of 1-year hazard ratios of different subgroups, as well as several degrees of EF, flow, Gr, AVA and comorbidities. Different degrees of left ventricular dysfunction and low gradient had significantly higher risk of mortality, while lower flow or area were not independently predictive. When considering different subtypes of AS, LF-LG AS had a more than twofold risk of mortality (HR 2,44 [1, 3-4, 42], $p<0,003)$ compared to HG. Out of the comorbidities, only patients with severe renal insufficiency (GFR $<30 \mathrm{ml} / \mathrm{min}$ ), or with moderate and 
severe paravalvular aortic regurgitation (AR) had higher risk of mortality, besides of advanced (80+) age. The hazard ratios are demonstrated on Table 4. 
Table 4

Hazard Ratios of 1-year mortality

\begin{tabular}{|c|c|c|c|c|}
\hline & & Hazard Ratio & $\mathrm{Cl} 95 \%$ & $\mathbf{p}$ \\
\hline \multirow[t]{3}{*}{ Flow } & $<25 \mathrm{ml} / \mathrm{m}^{2}$ & 1,30 & $0,74-2,28$ & 0,35 \\
\hline & $<30 \mathrm{ml} / \mathrm{m}^{2}$ & 1,13 & $0,94-1,84$ & 0,11 \\
\hline & $<35 \mathrm{ml} / \mathrm{m}^{2}$ & 1,18 & $0,96-1,44$ & 0,11 \\
\hline \multirow[t]{3}{*}{ EF } & $<30 \%$ & 2,22 & $1,12-4,40$ & 0,02 \\
\hline & $<40 \%$ & 1,83 & $1,17-2,87$ & 0,01 \\
\hline & $<50 \%$ & 1,56 & $1,10-2,21$ & 0,01 \\
\hline \multirow[t]{2}{*}{ Gradient } & $<30 \mathrm{mmHg}$ & 3,37 & $1,66-6,80$ & 0,001 \\
\hline & $<40 \mathrm{mmHg}$ & 1,84 & $1,15-2,95$ & 0,01 \\
\hline \multirow[t]{2}{*}{ Area } & $<0,5 \mathrm{~cm}^{2}$ & 0,78 & $0,49-1,22$ & 0,28 \\
\hline & $<0,6 \mathrm{~cm}^{2}$ & 0,89 & $0,70-1,14$ & 0,36 \\
\hline LF-LG AS * & & 2,44 & $1,34-4,42$ & 0,003 \\
\hline PLF-LG AS * & & 2,02 & $0,77-5,27$ & 0,15 \\
\hline NF-LG AS * & & 0,44 & $0,07-2,95$ & 0,40 \\
\hline Porcelain aorta & & 1,13 & $0,33-3,81$ & 0,85 \\
\hline $\mathrm{CHD}$ & & 0,89 & $0,73-1,10$ & 0,28 \\
\hline TIA/Stroke & & 0,89 & $0,72-1,46$ & 0,83 \\
\hline COPD & & 1,56 & $0,95-1,42$ & 0,08 \\
\hline Atrial fibrillation & & 0,98 & $0,67-1,42$ & 0,90 \\
\hline Diabetes mellitus & & 1,10 & $0,72-1,88$ & 0,66 \\
\hline $\mathrm{GFR}<30 \mathrm{ml} / \mathrm{min}$ & & 1,83 & $1,10-3,05$ & 0,02 \\
\hline NYHA class III-IV. & & 1,26 & $0,82-1,91$ & 0,29 \\
\hline Male sex & & 1,02 & $0,72-1,45$ & 0,89 \\
\hline Age $>/=80$ & & 1,99 & $1,09-3,64$ & 0,02 \\
\hline Paravalvular AR Grade 2+ & & 2.05 & $1,15-3,63$ & 0,01 \\
\hline MR Grade 2+ & & 1,47 & $0,92-2,35$ & 0,10 \\
\hline
\end{tabular}




\begin{tabular}{|lcc|}
\hline \multicolumn{1}{|c|}{ Hazard Ratio } & Cl 95\% & P \\
\hline $\begin{array}{l}\text { Abbreviations: CHD: coronary heart disease, COPD: chronic obstructive } \\
\text { regurgitation, MR: mitral regurgitation }\end{array}$ & \\
\hline * vs. HG AS & & \\
\hline
\end{tabular}

With logistic regression analysis - independent predictor of 1-year all-cause mortality

were moderate or severe paravalvular aortic regurgitation (AR) and severe renal failure (GFR $<30 \mathrm{ml} / \mathrm{min}$ ), while area, flow, EF, gradient, or other concomitant diseases were not statistically significant - as shown on Table 5. 
Table 5

Univariate and multivariate analysis of predictors of 1-year mortality

\begin{tabular}{|c|c|c|c|c|c|c|c|c|}
\hline & \multicolumn{4}{|c|}{ LINEAR REGRESSION } & \multicolumn{4}{|c|}{ MULTIPLE REGRESSION } \\
\hline & \multirow[t]{2}{*}{$\mathrm{p}$} & \multirow[t]{2}{*}{ B } & \multicolumn{2}{|c|}{$95.0 \%$ C. I. for B } & \multirow[t]{2}{*}{$\mathrm{p}$} & \multirow[t]{2}{*}{$\operatorname{Exp}(B)$} & \multicolumn{2}{|c|}{$\begin{array}{l}95 \% \text { C.I.for } \\
\operatorname{EXP(B)}\end{array}$} \\
\hline & & & Lower & Upper & & & Lower & Upper \\
\hline Area & 0,079 & $-0,0004$ & $-0,00043$ & 0,00782 & 0,08 & 1,0276 & 0,997 & 1,059 \\
\hline Flow & 0,100 & 0,00004 & $-0,00009$ & 0,00001 & 0,11 & 0,998 & 0,997 & 1,000 \\
\hline $\mathrm{EF}$ & 0,426 & $-0,001$ & $-0,005$ & 0,002 & & & & \\
\hline $\mathrm{Gr}$ & 0,577 & $-0,001$ & $-0,005$ & 0,003 & & & & \\
\hline $\begin{array}{l}\text { Coronary Heart } \\
\text { Disease }\end{array}$ & 0,100 & $-0,269$ & $-0,184$ & 0,019 & 0,10 & 0,5318 & 0,251 & 1,129 \\
\hline Previous Stroke/TIA & 0,998 & 0,000 & $-0,093$ & 0,093 & & & & \\
\hline COPD & 0,142 & 0,081 & $-0,027$ & 0,189 & & & & \\
\hline Atrial fibrillation & 0,379 & $-0,040$ & $-0,129$ & 0,049 & & & & \\
\hline Diabetes & 0,528 & 0,031 & $-0,066$ & 0,128 & & & & \\
\hline $\mathrm{GFR} « 30 \mathrm{ml} / \mathrm{min}$ & 0,039 & 0,117 & 0,006 & 0,228 & 0,04 & 2,2171 & 1,043 & 4,715 \\
\hline NYHA cl. III.-IV. & 0,932 & $-0,004$ & $-0,104$ & 0,095 & & & & \\
\hline Male & 0,910 & $-0,006$ & $-0,101$ & 0,090 & & & & \\
\hline Age & 0,118 & 0,007 & $-0,002$ & 0,015 & & & & \\
\hline Post-TAVI AR 2+ & 0,046 & 0,116 & 0,002 & 0,230 & 0,04 & 2,3363 & 1,048 & 5,209 \\
\hline Pre-TAVI MR 2+ & 0,485 & 0,038 & $-0,069$ & 0,145 & & & & \\
\hline Porcelain aorta & 0,697 & 0,039 & $-0,158$ & 0,235 & & & & \\
\hline
\end{tabular}

With the analysis of the interdependence of different echocardiographic parameters there was a moderate and positive correlation between ejection fraction and flow $(R=0,541, p<0,0001), E F$ and gradient $(R=0,485, p<0,0001)$, flow and area $(R=0,495, p<0,0001)$, and an inverse but moderate correlation between area and gradient $(R=0,454, p<0,0001)$, but the correlation of flow and gradient was weak $(R=0,206, p<0,0001)$. These correlations are demonstrated on Fig. 5 .

Hemodynamic parameters after TAVI

Of 249 patients who survived the first year after TAVI 199 (79,8\%) underwent echocardiographic control at 1-year follow-up. The mean aortic gradient decreased (baseline $51,3+/-16,7 \mathrm{mmHg}$ vs. $8,7+/-3,6 \mathrm{mmHg} \mathrm{p}$ 
$<0,0001$ ), the aortic valve area increased (baseline 0,54+/-0,1 cm2 vs. 1,65+/-0,27 cm2 $p<0,0001$ ). The LVEF slightly improved in HG and LF-LG groups, but remained unchanged in PLF-GL and NF-LG groups. Changes in LVEF are provided in Fig. 6 . .

On the other hand, when classifying our patients solely by their initial EF, a clinically relevant and statistically significant improvement of EF could have been demonstrated in every ten-percent cluster under EF $60 \%$, as demonstrated on Fig. 7. .

\section{Discussion:}

Patients with LF-LG AS represent a challenging subpopulation with a poor prognosis when undergoing conservative or surgical treatment. TAVI is an alternative option, however, due to controversial data, the outcomes of TAVI and predictors of late mortality have not been clarified yet [24.]. Different risk algorithms were suggested for risk stratification based on clinical and laboratory findings and LVEF, but none of them used Gr or SVI for risk stratification [13.-14.]. Since it is still uncertain whether these patients benefit from less invasive treatment, we aimed to evaluate the prognostic impact of different SVI-gradient AS patterns after TAVI. The main finding is that 30-day, 1-year and 3-year all-cause mortality was the highest in the LF-LG group. Our 1-year mortality results are comparable to larger registries [25.,26.]. The 30-day and 1-year mortality rate of the LF-LG subgroup was about 2-3 times higher than in the HG AS patients.

Reduced LVEF was found to be a predictive factor of 30-day and 1-year mortality after TAVI in several studies, [26.27.]. In a recent meta-analysis of 6898 TAVI patients low SVI, low gradient, and low EF were each associated with higher mortality after TAVI [28.].

In our study the PLF-LG group represented only 3,0\% of the whole patient population. The 1-year mortality was worse than in patients with HG AS, but better than in the LF-LG group. The small number of PLF-LG patients and endpoints in this group doesn't allow us to draw further conclusions. The NF-LG group was heterogenous by left ventricular dimensions, with moderate LV dysfunction, but had the most favorable outcomes, similarly with previous studies [9.]. For this subtype of AS, there is no recommendation for intervention, nevertheless these patients may also have better outcomes with intervention [10.]. In surviving patients with initial LV dysfunction, the LVEF significantly improved 1 year after TAVI. This observation corresponds with several previous studies [24.,26.,27.].

A relatively large proportion (59\%) of our patients had low flow. The high prevalence of LF in the AS population is the consequence of frequent comorbidities and associated complications such as hypertrophy, diastolic dysfunction, ventricular dyssynchrony, impaired longitudinal function. Nevertheless, there are well-known inherent inconsistencies of the AS severity criteria in the guidelines.

We could not demonstrate the negative effect of low SVI, which is not surprising considering the high percentage $(53,6 \%)$ of low flow condition in the HG group, in which the prognosis was better. On the other hand, we found moderately strong correlation between EF and flow, EF and gradient, flow and area and 
between area and gradient, so these parameters must not be emphasized solely. Beyond that, HG or LFLG criteria were useful in the prediction of outcome. Our results correspond with one previous study in which AS subtype independently influenced long-term mortality, whereas EF, flow or low gradient alone did not [29.].

In our study only moderate or severe paravalvular AR, and severe renal insufficiency were independent predictors of 1-year mortality. This finding is consistent with the results of larger registries [20.,30.].

\section{Limitations:}

The main limitation of our study is the relatively smaller sample size, and its single-center character. We could not estimate the risk of the PLF-LG AS, since this subgroup was small, and only 3 of them reached primary endpoint at 1-year. Despite prospective data collection, the analysis was retrospective and therefore subject to the limitations of an observational study. Besides limitations, the strenghts of our study are the complete analysis of consecutive patients, the $100 \%$ mortality tracking, and the long followup period up to 115 months.

\section{Conclusions:}

Our study demonstrates the impact of different subtypes of AS on outcome after TAVI. All-cause mortality was lowest in patients with HG AS, it was intermediate in patients with PLF-LG AS and highest in patients with LF-LG AS. The classification of patients into flow-gradient pattern might be useful for risk stratification before TAVI. Considering the high 1-year all-cause mortality in patients with LF-LG AS, a careful selection is warranted. In patients with LF-LG AS closer follow-up and active medical treatment of left ventricular dysfunction is needed after TAVI, in order to improve survival. Improvement of initial left ventricular dysfunction can be expected after TAVI regardless of its severity.

\section{Declarations}

Funding: None

Conflicts of interest: The authors declare that they have no conflict of interest.

Ethics approval All procedures performed in studies involving human participants were in accordance with the ethical standards of the Institutional Ethics Committee and with the 1964 Helsinki Declaration and its later amendments. Ethical approval was waived by the local Ethics Committee in view of the retrospective nature of the study and all the procedures being performed were part of the routine care.

Consent to participate: All patients provided written informed consent

Consent for publication Not applicable

Availability of data and material Not applicable 
Code availability Not applicable

\section{Authors' contributions}

All authors contributed to the study conception and design. Material preparation, data collection and analysis were performed by Matyas Pal MD., Gabor Dekany MD, and Adrienn Mandzak MD. . The first draft of the manuscript was written by Matyas Pal MD. and all authors commented on previous versions of the manuscript. All authors read and approved the final manuscript.

\section{References}

1. Baumgartner $\mathrm{H}$, Hung J, Bermejo J, Chambers JB, Evangelista A, Griffin BP et al.: Echocardiographic assessment of valve stenosis: EAE/ASE recommendations for clinical practice.

J. Am. Soc. Echocardiogr. 2009; 22:1. -23. doi: 10.1016/j.echo.2008.11.029

2. Pibarot P, Dumesnil JG.: Low-flow, low-gradient aortic stenosis with normal and depressed left ventricular ejection fraction.

J. Am. Coll. Cardiol.: 2012;60:1845.-53. doi 10.1016/j.jacc.2012.06.051

3. Hachicha Z, Dumesnil JG, Bogaty P, Pibarot P.: Paradoxical low flow, low gradient severe aortic stenosis despite preserved ejection fraction is associated with higher afterload and reduced survival.

Circulation 2007; 115:2856. -2864. doi.org/10.1161/CirculationAHA.106668681

4. Clavel MA, Dumesnil JG, Capoulade R, Mathieu P, Sénéchal M, Pibarot P: Outcome of patients with aortic stenosis, small valve area and low-flow, low-gradient despite preserved left ventricular ejection fraction.

J. Am. Coll. Cardiol. 2012; 60:1259. -1267. doi: 10.1016/j.jacc.2011.12.054

5. Pereira JJ, Lauer MS, Bashir M, Afridi I, Blackstone EH, Stewart WJ et al.: Survival after aortic valve replacement for severe aortic stenosis with low transvalvular gradients and severe left ventricular dysfunction.

J. Am. Coll. Cardiol. 2002;39(8):1356-63. doi:10.1016/s0735-1097(02)01759-x

6. Vaquette B, Corbineau H, Laurent M, Lelong B, Langanay $\mathrm{T}$, de Place $\mathrm{C}$ et al. : Valve replacement in patients with critical aortic stenosis and depressed left ventricular function: predictors of operative risk, left ventricular function recovery, and long term outcome.

Heart 2005; 91:1324. -1329. dx.doi.org/10.1136/hrt.2004.044099

7. Baumgartner H, Falk V, Bax JJ, De Bonis M, Hamm C, Holm PJ et al.: 2017 ESC/EACTS Guidelines for the management of valvular heart disease

Eur. Heart J. 2017: 38:2739-2791. doi.org/10.1093/eurheartj/ehx636 
8. Nishimura RA, Otto CM, Bonow RO, Carabello BA, Erwin JP, Guyton RA et al. : 2014 AHA/ACC guideline for the management of patients with valvular heart disease: a report of the American College of Cardiology/American Heart Association Task Force on Practice Guidelines J. Am. Coll. Cardiol. 2014;63:57.-185 doi: 10.1016/j.jacc.2014.02.536

9. Lancellotti P, Magne J, Donal E, Davin L, O'Connor K, Rosca M et al.: Clinical outcome in asymptomatic severe aortic stenosis insights from the new proposed aortic stenosis grading classification.

J. Am. Coll. Cardiol. 2012;59:235.-243. doi: 10.1016/j.jacc.2011.08.072

10. Dayan V, Vignolo G, Magne J, Clavel MA, Mothy D, Pibarpot P: Outcome and impact of aortic valve replacement in patients with preserved LVEF and low-gradient aortic stenosis J. Am. Coll. Cardiol. 2015; 66(23): 2594-2603. doi.org/10.1016/j.jacc.2015.09.076

11. Leon MB, Smith CR, Mack M, Miller DC, Moses JW, Svensson LG et al.: for the PARTNER Trial Investigators: Transcatheter aortic-valve implantation for aortic stenosis in patients who cannot undergo surgery

N. Engl. J. Med. 2010; 363:1597.-1607. doi: 10.1056/NEJMoa1008232

12. Collas VM, Van De Heyning CM, Paelinck BP, Rodrigus IE, Vrints CJ, Bosmans JM.: Validation of transcatheter aortic valve implantation risk scores in relation to early and mid-term survival: a singlecentre study. Interact.CardioVasc. Thorac. Surg. 2016; 22: 273-279. doi: 10.1093/icvts/ivv340

13. D'Ascenzo F, Capodanno D, Tarantini G, Nijhoff F, Ciuca C, Rossi ML et al.: Usefulness and validation of the survival posT TAVI score for survival after transcatheter aortic valve implantation for aortic stenosis.

Am. J. Cardiol. 2014; 114:1867-74. doi: 10.1016/j.amjcard.2014.09.031

14. Capodanno D, Barbanti M, Tamburino C, D'Errigo P, Ranucci M, Santoro G et al.: on behalf of the OBSERVANT Research Group : A simple risk tool (the OBSERVANT score) for prediction of 30-day mortality after transcatheter aortic valve replacement.

Am. J. Cardiol. 2014; 113:1851-8. doi: 10.1016/j.amjcard.2014.03.014

15. Herrmann HC, Pibarot P, Hueter I, Gertz ZM, Stewart WJ, Kapadia S et al.: Predictors of Mortality and Outcomes of Therapy in Low Flow Severe Aortic Stenosis: A PARTNER Trial Analysis, Circulation 2013;127(23):2316-2326. doi:10.1161/CirculationAHA.112.001290.

16. Le Ven F, Freeman M, Webb J, Clavel MA, Wheeler M, Dumont E et al.: Impact of low-flow on the outcome of high-risk patients undergoing transcatheter aortic valve replacement J.Am.Coll.Cardiol. 2013; 62: 782.-788. doi: 10.1016/j.jacc.2013.05.044.

17. Gotzmann M, Rahlmann P, Hehnen T, Müller P, Lindstaedt M, Mügge A et al.: Heart failure in severe aortic valve stenosis: prognostic impact of left ventricular ejection fraction and mean gradient on 
outcome after transcatheter aortic valve implantation.

Eur. J. Heart. Fail. 2012; 14:1155-1162. doi:10.1093/eurjhf/hfs108

18. Amabile N, Ramadan R, Ghostine S, Cheng S, Azmoun A, Raoux F et al.: Early and mid-term cardiovascular outcomes following TAVI: Impact of pre-procedural transvalvular gradient.

Int. J. Cardiol. 2012; 167:687. -692. doi: 10.1016/j.ijcard.2012.03.066

19. Moat NE, Ludman P, de Belder MA, Bridgewater B, Cunningham AD, Young CP et al.: Long-Term Outcomes After Transcatheter Aortic Valve Implantation in High-Risk Patients with Severe Aortic Stenosis J. Am. Coll. Cardiol. 2011; 58:2130-8. doi: 10.1016/j.jacc.2011.08.050

20. Mack MJ, Leon MB, Thourani VH, Raj Makkar RR, Susheel K. Kodali SK et al.: on behalf of the PARTNER 3 Investigators. Transcatheter Aortic-Valve Replacement with a Balloon-Expandable Valve in Low-Risk Patients.

N. Engl.J.Med. 2019;380:1695-1705. doi: 10.1056/NEJMoa1814052

21. Popma JJ, Deeb GM, Yakubov SJ, Mumtaz M, Gada H, O'Hair D et al.: on behalf of the Evolut Low Risk Trial Investigators. Transcatheter Aortic-Valve Replacement with a Self-Expanding Valve in Low-Risk Patients

N. Engl. J. Med. 2019; 380:1706-1715. doi: 10.1056/NEJMoa1816885

22. Lang RM, Bierig M, Devereux RB, Flachskampf FA, Foster E, MD, Pellikka PA et al.: Recommendations for chamber quantification: a report from the American Society of Echocardiography's Guidelines and Standards Committee and the Chamber Quantification Writing Group

J. Am. Soc. Echocardiogr. 2005; 18:1440.-1463.

doi: 10.1016/j.echo.2005.10.005.

23. Kappetein AP, Head SJ, Généreux P, Piazza NA, van Mieghem NM, Blackstone EH et al.: Updated standardized endpoint definitions for transcatheter aortic valve implantation: The Valve Academic Research Consortium-2 consensus document (VARC-2) J Am Coll Cardiol 2012;60(15): 1438-54.doi: 10.1016/j.jacc.2012.09.001.

24. Elhmidi Y, Piazza N, Krane M, Deutsch MA, Mazzitelli D, Lange R et al.: Clinical presentation and outcomes after transcatheter aortic valve implantation in patients with low flow/low gradient severe aortic stenosis.

Catheter Cardiovasc. Interv. 2014;84:283.-290. doi: 10.1002/ccd.25366

25. Tamburino C, Capodanno D, Ramondo A, Petronio AS, Ettori F, Santoro G et al.: Incidence and predictors of early and late mortality after transcatheter aortic valve implantation in 663 patients with severe aortic stenosis.

Circulation 2011; 123:299-308. doi: 10.1161/CirculationAHA.110.946533. 
26. Lauten A, Zahn R, Horack M, Sievert H, Linke A, Ferrari M et al.: on behalf of the German Transcatheter Aortic Valve Interventions Registry Investigators : Transcatheter Aortic Valve Implantation in Patients With Low-Flow, Low-Gradient Aortic Stenosis JACC:Cardiovascular Interventions,2012:5:552 559.doi10.1016/j.jcin.2012.04.001.

27. Ewe SH, Ajmone Marsan N, Pepi M, Delgado V, Tamborini G, Muratori M et al.: Impact of left ventricular systolic function on clinical and echocardiographic outcomes following transcatheter aortic valve implantation for severe aortic stenosis.

Am. Heart J. 2010; 160:1113-1120. doi:10.1016/j.ahj.2010.09.003

28. Sannino A, Gargiulo G, Schiattarella GG, Brevetti L, Perrino C, Stabile E et al.: Increased mortality after transcatheter aortic valve implantation (TAVI) in patients with severe aortic stenosis and low ejection fraction: a meta-analysis of 6898 patients.

Int. J. Cardiol. 2014; 176:32.-39. doi.org/10.16/j.ijcard.2014.06.017

29. Puls M, Korte KP, Bleckmann A, Huenlich M, Danner BC, Schoendube F et al.: Long-term outcomes after TAVI in patients with different types of aortic stenosis: the conundrum of low flow, low gradient and low ejection fraction

Eurolntervention 2017 Jun 20;13(3):286-293. doi: 10.4244/EIJ-D-16-00801

30. Zahn R, Gerckens U, Linke A, Sievert H, Kahlert P, Hambrecht R et al.: German Transcatheter Aortic Valve Interventions - Registry Investigators: Predictors of One-Year Mortality After Transcatheter Aortic Valve Implantation for Severe Symptomatic Aortic Stenosis

Am J Cardiol 2013; 112:272-279 dx.doi.org/10.1016/j.amjcard.2013.

\section{Figures}

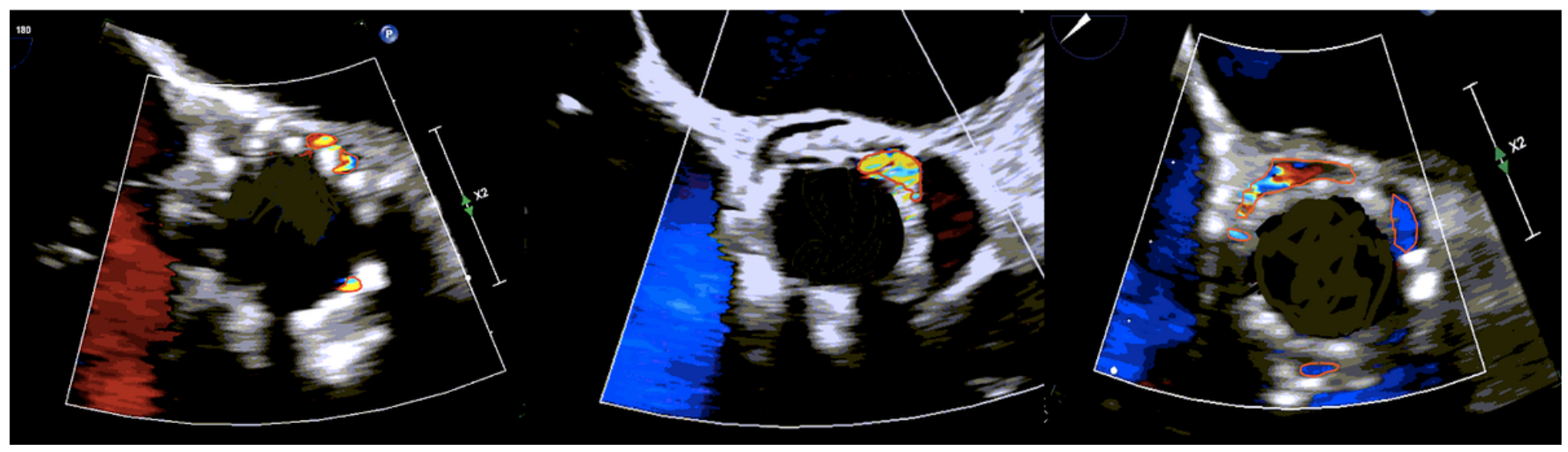

Figure 1

Mild-, Moderate- and Severe Paravalvular Regurgitation 


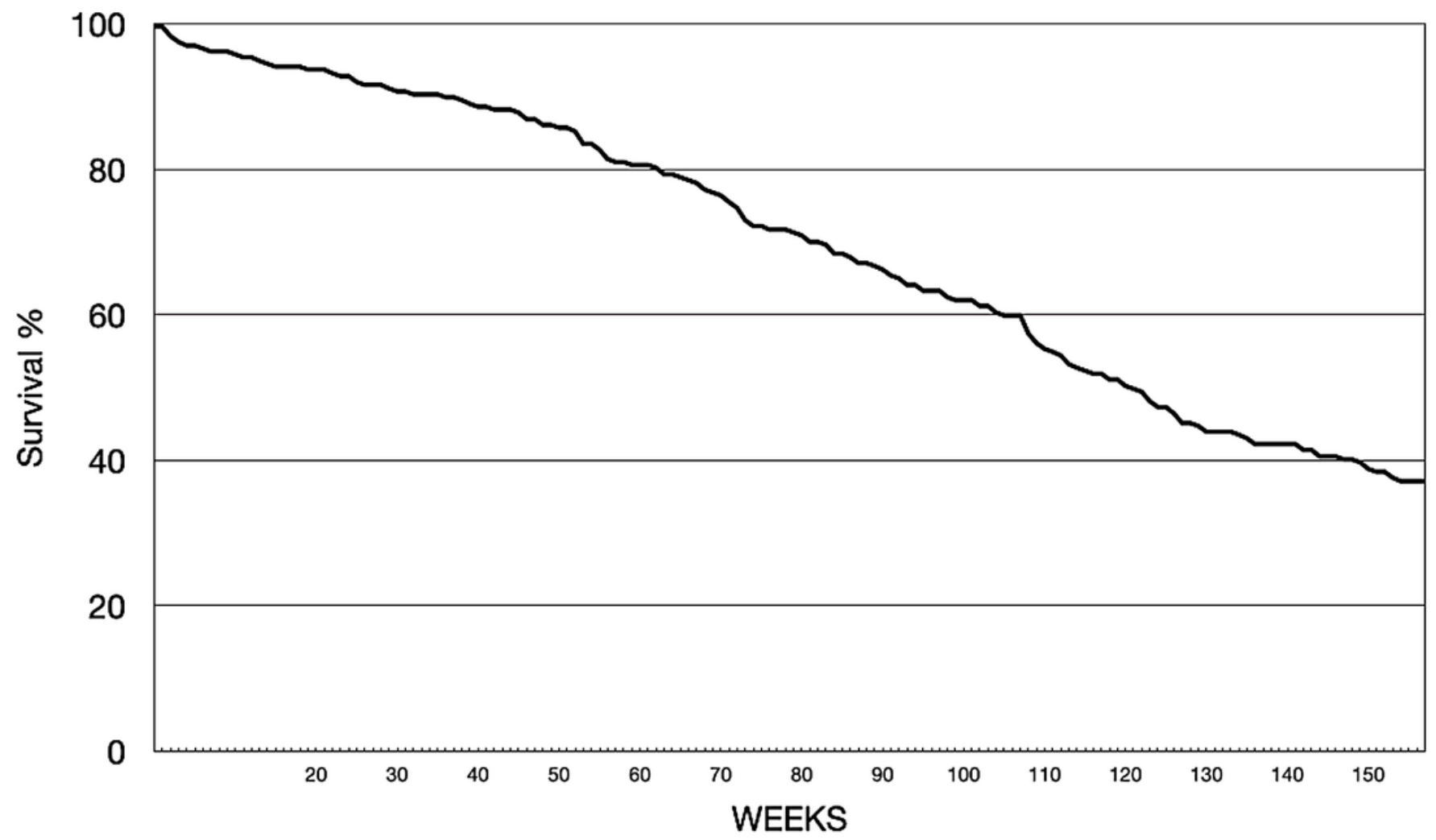

Figure 2

Kaplan Meier survival curve of the whole patient group 


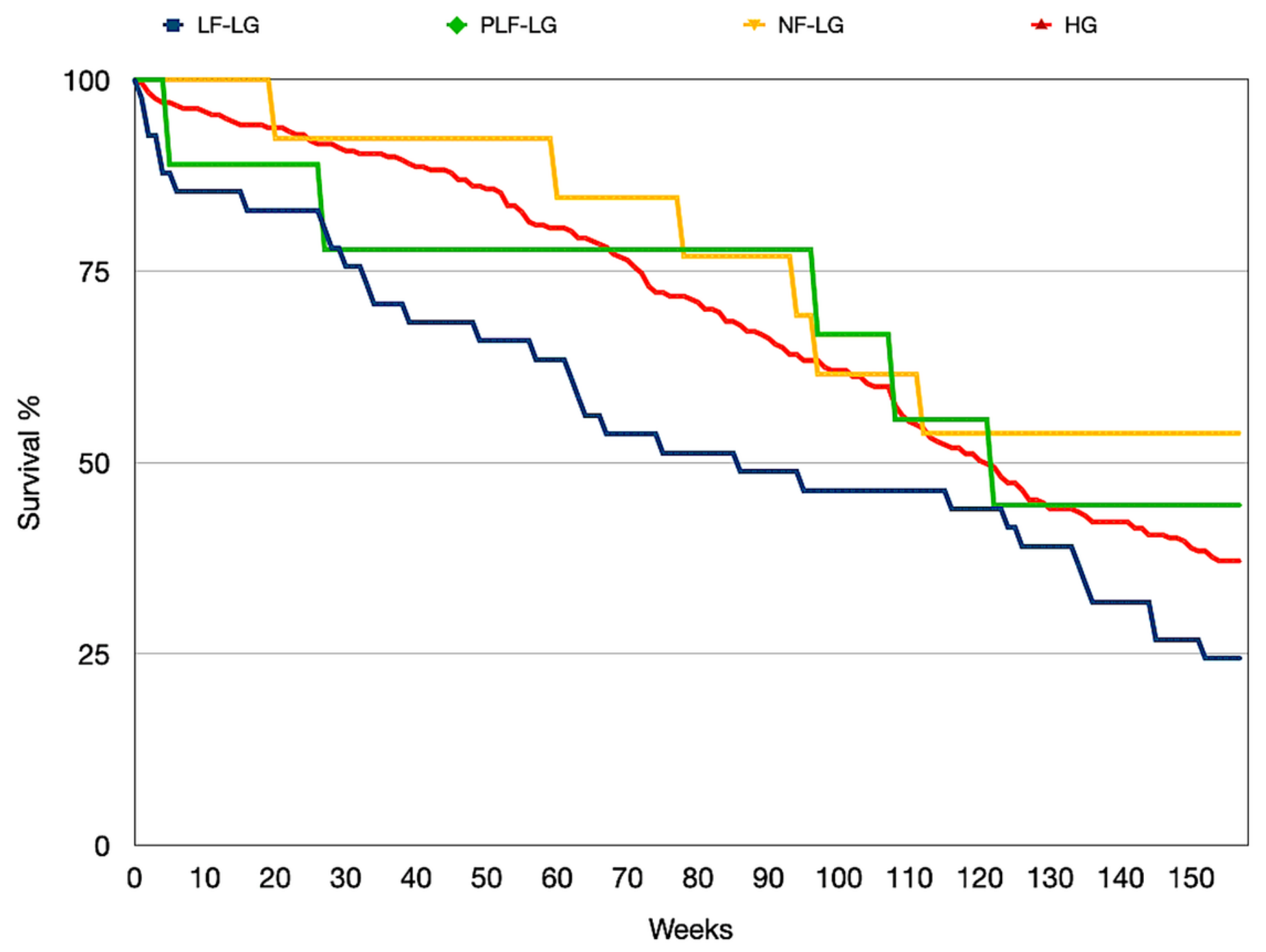

Figure 3

Survival curves of AS subgroups 


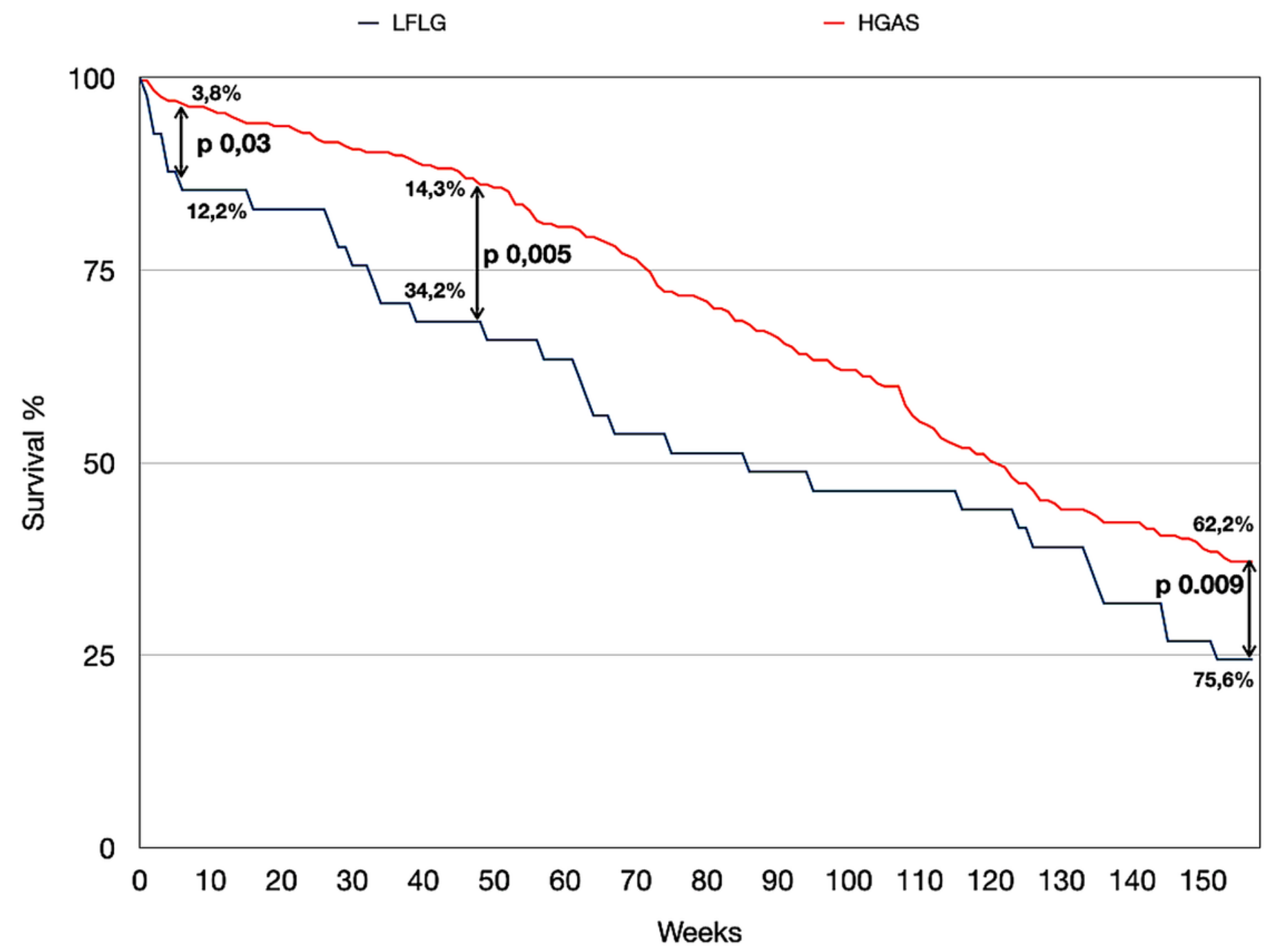

Figure 4

Survival differences of HG and LF-LG groups 

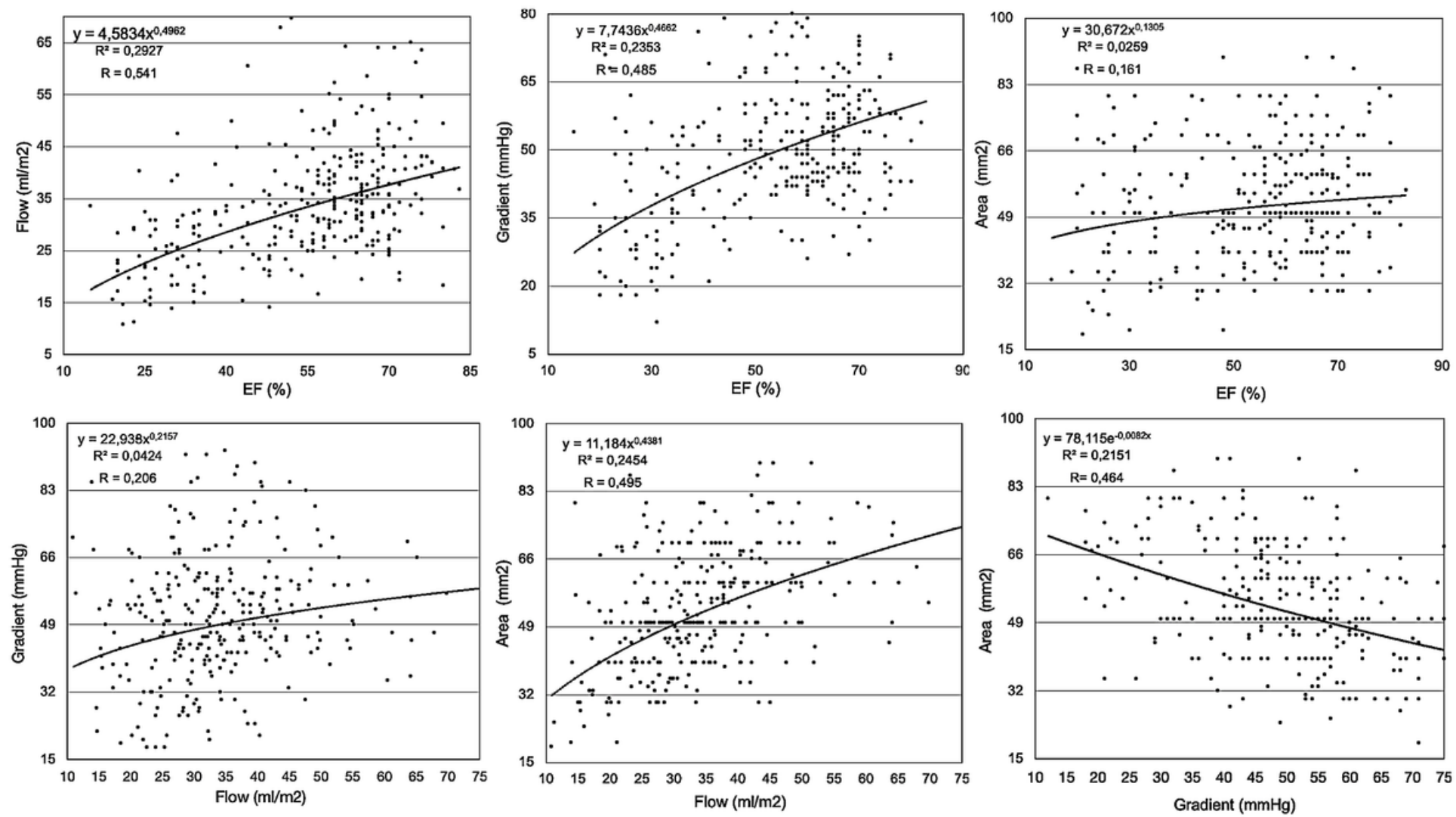

Figure 5

Correlations of EF, Flow, Gradient and Area 


\section{Changes of EF}

$80 \%$

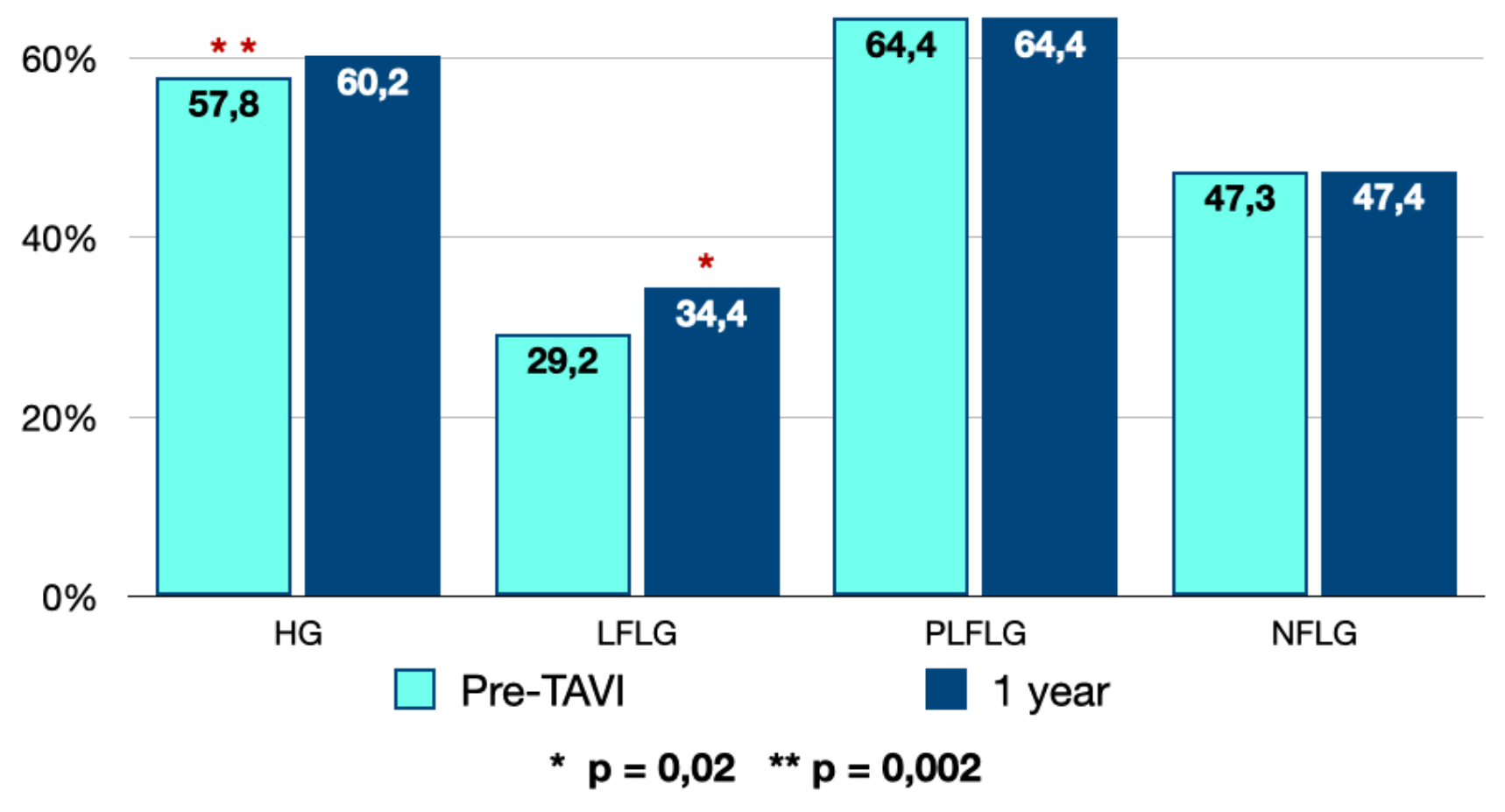

Figure 6

Changes of LVEF in the subgroups 
$80 \%$

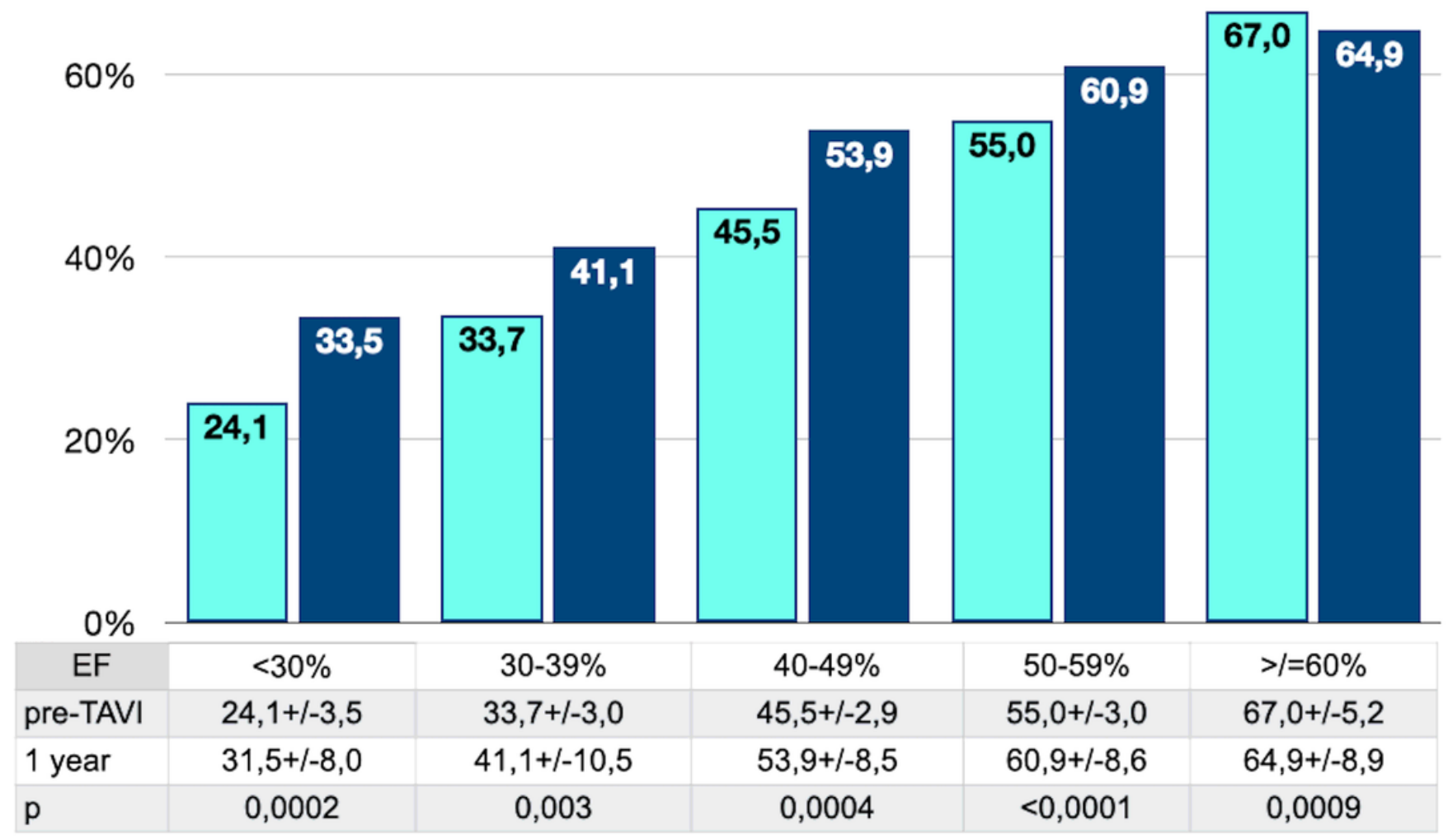

Figure 7

Changes of EF in $10 \%$ clusters 